\title{
Microscopic Findings Specimen Condition
}

National Cancer Institute

\section{Source}

National Cancer Institute. Microscopic Findings Specimen Condition. NCI Thesaurus.

Code C117592.

A characteristic that refers to the physical and organoleptic state of a biospecimen used for a microscopic assessment. 